\title{
The Significance of Architectural Approach to the Effects of Earthquake and Materials in the Design and Positioning of Gateways
}

\author{
Ahmad Mirza Kuchak Khoshnevis ${ }^{1}$, Omid Pourebrahim ${ }^{2}$, \\ ${ }^{1}$ Institute of Cultural Heritage, Tehran, Iran \\ ${ }^{2}$ Architecture department, PNU Hormozgan, Hormozgan, Iran
}

Email address:

a.m.khoshnevis@gmail.com (A. M. K. Khoshnevis),pourebrahim.omid@gmail.com (O. Pourebrahim)

\section{To cite this article:}

Ahmad Mirza Kuchak Khoshnevis, Omid Pourebrahim. The Significance of Architectural Approach to the Effects of Earthquake and Materials in the Design and Positioning of Gateways. International Journal of Science, Technology and Society. Special Issue: Research and Practice in Architecture and Urban Studies in Developing Countries. Vol. 3, No. 2-1, 2015, pp. 52-57. doi: 10.11648/j.ijsts.s.2015030201.21

\begin{abstract}
According to the basic principles of earthquake engineering, during earthquake forces in addition to the gravity force are generated in proportion to the weight of structural members and the seismic acceleration as a result of the vibration caused to all structural members including gateways. The distribution and intensity of such forces depend on the architecture (shape, form, size and aspect ratio) of the building. Accordingly, it seems that in designing gateways, architects not only shall consider the operational and aesthetic dimensions of the member, but also consider shall pay attention to the mutual effects of building materials and earthquake. By designing an appropriate form and by considering the dimensional proportion and earthquake engineering principles it is possible to mitigate earthquake-induced damages. Therefore, architectural engineering plays the key role in maintaining the balance and sustainability of structures and optimizing plans. The significance of the effects of earthquake to the design and positioning of gateways by architectural engineering can be explained as follows: 1) The gateway is the placeholder for doors and openings (which are very light-weight and flexible elements) and thus it not only reduces earthquake forces due to the lightness of its components but also allows for the transfer and flow of stresses to the margins and surroundings; 2) Since even seconds matter for saving the lives of humans during earthquake, accurate positioning of gateway and its dimensions can influence the speed of movement through the gateway; 3 ) Since gateway provides a free space and its surroundings are formed of resistant shapeable materials, it is possible to use it as a shelter at the time of earthquake; 4) In this research it was tried to use the basic principles and relations associated with the resistance of materials, the principles of earthquake engineering (for the theoretical study), and also documentary images of earthquake (for the field study) to study the effects of shape and aspect ratio of gateways on the forces and stresses caused by earthquake.
\end{abstract}

Keywords: Gateway, Earthquake, Architecture, Materials

\section{Introduction}

Gateways are among most important constituents of all buildings and are used to connect spaces and provide for the movement (transfer) of human and his accessories.

The Persian word "Dargah" is a combination of two words: "Dar" (English: Door; it refers to a metal, wooden or element used for traffic or blocking a restricted and constrained space) and the word "Gah" (which is a suffix referring to a place). In architecture, gateway refers to a part of building which provides for the movement of humans and transfer of objects and elements (such as light and air) between two separate adjacent places or between the interior space and exterior space of a building (Dehkhoda Encyclopedia). The peripheral design and outline of a gateway is visible to the audiences at the time of movement. Gateway, as the element that allows for entering into spaces, can represent the overall image of the building if designed properly. It can also encourage the public to enter a building and visit its interior space. This advantage has turned gateway into a place suitable for giving information and defining cultural elements using artistic expressions in the form of architecture, line, and painting. 
From the past to the present gateways and facades have been manifested in the form of gateways, city symbols (such as Quran Gate), national monuments (such as the Azadi Square in Tehran, Iran), and entrance of public places (such as education, cultural and artistic centers). These manifestations have attracted the attention of architects and have reflected the identity of different places. For instance, Figure (1-a) depicts city gate while Figure (1-b) shows the façade of the Khorshid Library in Kerman.
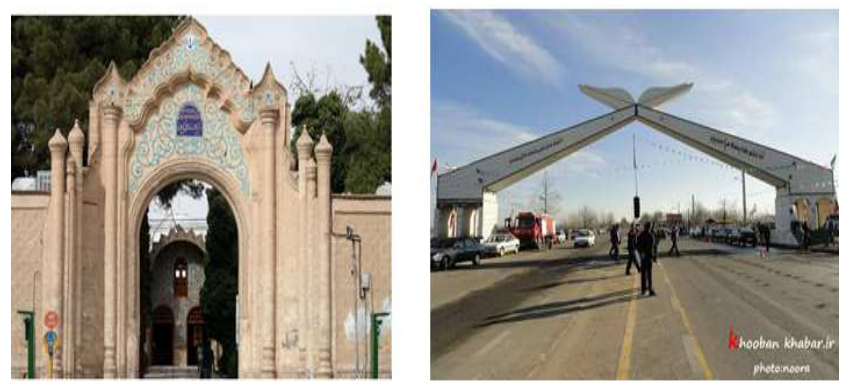

Figure (1). a). Entrance of Khoshkbijar City (source: www.khoobankhabarir) ;b) Façade of Khorshid Library in Kerman (source: author)

The architecture existence and sustainability as well as the cultural and artistic identity of gateways depend on the durability and strength of their constituent materials as well as the firmness, balance and resistance of its components to gravity loads and lateral forces, especially earthquake forces. Therefore, the attitude of architectural engineering to the type of materials and earthquake forces influencing the design and layout of gateways guarantees the survival and sustainability of the form as well as the architectural and cultural contents of these structural elements.

\section{Evolution of Gateways}

Since the overall geometry and shape of each element depend on the dimensional proportion and the size of components and sides and since the design and development of this geometry depend on the knowledge of applied forces, tools, the existing facilities and the mechanical properties of the materials used in the structure, architectural models of gateways vary depending on the time and place as well as the available materials and operational facilities. Accordingly, in the following comes a brief review of the evolution of gateways.

The overall schema of the early gateways was derived from cave entrances in the primitive ages. The age and size of the early gateways were also a function of resistance and ductility of the materials used in the body of natural caves in a limit equilibrium state. Examples of such gateways include the entrances to the ancient village of Meymand in Shahr-e Babak County (Fig. 2).

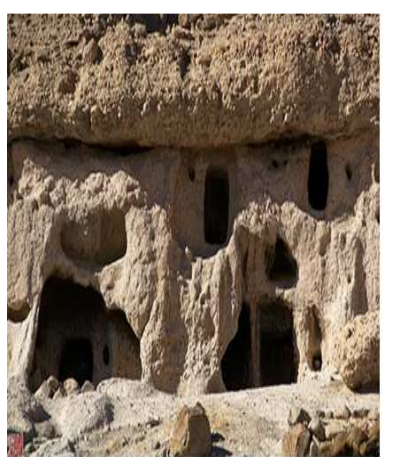

Figure (2). Examples of entrances to the ancient village of Meymand in Shahr-e Babak County (source: www.chn.ir)

As human gained access to the means of crushing and cutting objects, he started to combine pieces of rock, wood, etc. to build shelters. The entrances of such places were also formed based on the type of the pieces used in the structure (Zareyi, 2012). When human became familiar with the properties of mud and the fact that it hardness when exposed to air and heat, he used it to connect pieces of rock and wood so as to create a more coherent structure. The invention of adobe and the shaping of mud was the beginning of production of artifacts that were used as models in the construction of gateways. Use of materials such as lime and plaster and the production of brick can be considered the breakthrough in the building industry. These discoveries enabled human to determine the shape and size of building components. With the introduction of metals and specially copper, bronze and iron, human started to use these elements in combination with previously known elements to enhance the strength and ductility of structural members such as gateways (Zareyi, 2012).

The scientific revolution, the development of different sciences (e.g. physics, chemistry, etc.), the invention of tools and the production of new materials (such as cement and steel) along with the discovery of principles governing the balance and sustainability of elements and components, enabled human to further discover the relationship between shapes, sides, dimensions, materials properties, and acting forces. These advancements enabled human to build structures with varying components, shapes and sizes. The combination of scientific theories with scientific methods (procedures) led to the formation of engineering fields (such as fields dealing with materials, mechanics, structures, etc.) that used computer for analyzing and processing the data and also for solving equations. These developments also enabled architects to actualize their creative ideas of any kind (including ideas about the design of gateways), shape and size in relation to the existing ideas and models.

\section{Shape of Gateways}

Gateways generally consist of a horizontal foundation (that bears the traffic) and walls or perpendicular columns or almost vertical columns that stand on the side. It has an arch ceiling made up of building materials. Examples of gateways 
can be seen in historical buildings. Figure (3-a) shows an example of fully arched gateways in the Meymand Village while Figure (3-b) depicts an example of a gateway with vertical piers and an arched ceiling in the Sassanid fortress in Saryazd.
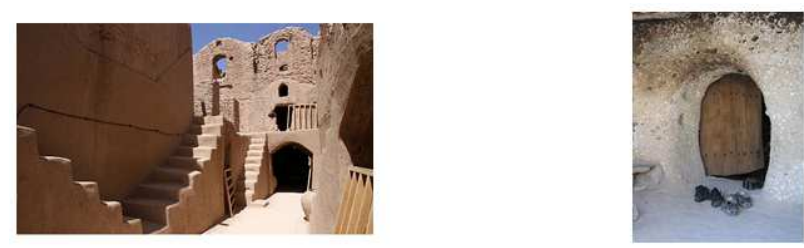

Figure (3). a) The fully arched gateways in the Meymand Village of Shahr-e Babak County, b) A gateway with vertical piers and an arched ceiling in the Sassanid fortress in Saryazd (source: www.goftarga.ir)

Although pieces of wood were previously used in the façade of gateways with horizontal ceiling (flat ceiling) with narrow spans, the introduction of strong and elastic materials provided for the construction of gateways with arbitrary shapes and span lengths.
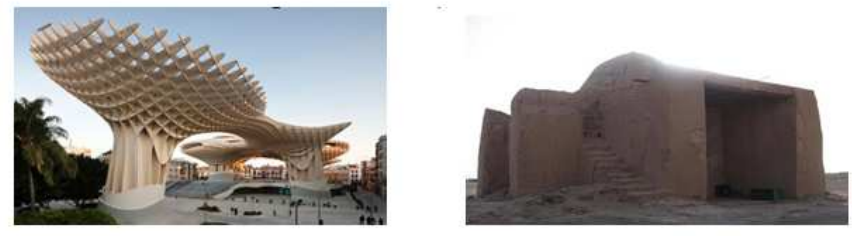

Figure (4). a) Imam Zadeh Ivanaki Gateway in Ivanaki, and b) The largest wood structure in the world (Spain)

\section{Gateway: Loading and Stress Discharge}

In general, forces and loads acting on the components and body of gateways include gravity loads (forces that exerted by the weight of materials and fixed/permanent elements, which are known as the dead loads along with the forces exerted by the weight of dynamic and non-fixed objects, which are known as live loads) and lateral loads (which are induced by earthquake, wind and explosion). The sum (result) of stresses caused by such forces along with gravity stresses leads to an increase in these forces and change of their direction and distribution. Consequently, the total force may exceed the allowable range of materials and lead to damage and destruction [5]. Gateway acts as a frame in reaction to the exerted forces. At the time of earthquake, in addition to gravity loads, seismic movements and inertia forces induce axial stresses (tensile or compressive stress) and shear stress at different parts of the frame. These stresses are the result of bending, shearing, and torsion and can be calculated as follows:

$$
\sigma=\frac{P}{A} \pm \frac{M}{W_{i}}
$$

Relation (1)

$$
\tau=\frac{V}{A}+\frac{T}{W_{g}}
$$

Where, $\mathrm{P}$ and $\mathrm{V}$ denote the axial and shear forces, respectively. $\mathrm{M}$ shows the torsional moment and $\mathrm{T}$ shows the bending moment. In addition, wi, wg and A also denote the bending modulus, the shear modulus and the surface area, respectively. $\sigma$ and $\tau$ also stand for the axial stress and shear stress. The combination of the stress values obtained through the above relations indicates that the result of shear stresses induces diagonal strain and bending-induced strain. These strains cause diagonal cracks due to the limited strength and ductility of materials. In order to determine the type and amount of internal stresses at different parts of the gateway it is possible to both use analytic methods and develop models in accordance with gateway shape and loads exerting on it. It is therefore possible to determine the type and amount of internal stresses at different parts using numerical methods and associated software.

\section{The Strength and Behavior of Building Materials}

Based on their response to forces and stresses, building materials can be classified into the following categories:

Fragile and brittle materials: These materials (such as brick) have a relatively high compressive strength and demonstrate slight tensile strength and ductility. The shear strength of these materials is a function of cohesion, friction coefficient, and compressive forces acting on shear surfaces. The simplest relation that expresses the ultimate strength of these materials is the Coulomb relation which is written as follows:

$$
\tau=c+\mu \times \sigma
$$

Relation (3)

Where, $\tau$ is the shear strength, $\sigma$ is the compressive stress acting on the shear surface, $\mu$ is the friction coefficient and $c$ is the cohesion of the environment being sheared. This relation indicates that with an increase in the compressive strength, the shear strength increases as well. Figure (4) shows the diagram for this relation.

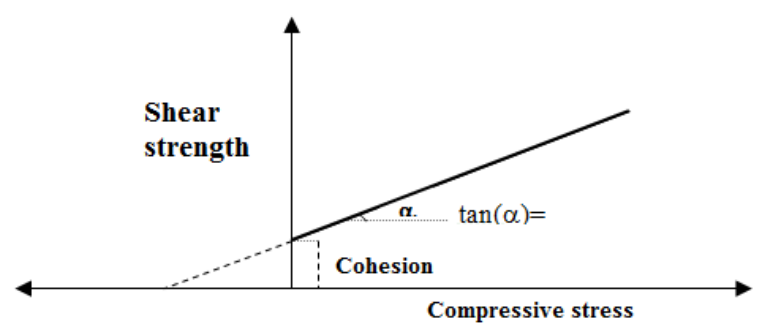

Figure (5). Diagram for the Coulomb Relation (source: [5])

Ductile materials (such as steel): These materials demonstrate satisfactory compressive strength, tensile strength, shear strength and ductility [5]. The simplest relation, which gives a one-dimensional expression of the mechanical properties of these materials is the Young's 
relation.

$$
\sigma=E \times \mathcal{E}
$$

Where, $\sigma$ denotes the axial stress, $\mathrm{E}$ is the Young modulus and $\varepsilon$ is the relative axial deformation of the element.

In these materials an increase in the stress leads to a relative proportional deformation which grows until the plastic phase, where it demonstrates deformations as the stress remains invariant. Later on with an increase in the stress the material fails. The combination of brittle elements with these elements contributes to the increase in the resistance and ductility of the elements. Figure (5) shows the schematic behavior of type I materials in comparison with the combination of the two aforementioned materials.

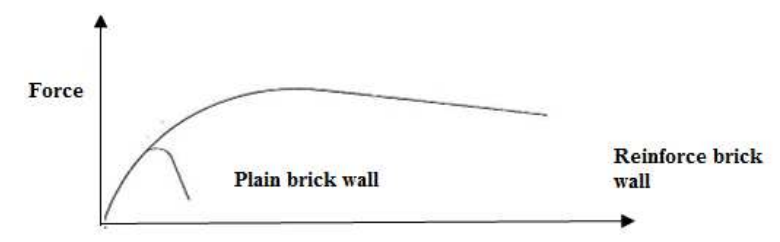

Displacement

Figure (6). The schematic behavior of brittle materials as compared to their combination with ductile materials (source: [5])

Since the elements of gateway (the sides and ceiling) are three dimensional and thus have a length, width and thickness, their bend and shear strengths are influenced by the combination of gravity and earthquake loads and can be calculated as follows:

$$
\begin{aligned}
& M_{u}=\frac{\sigma \times t \times L^{2}}{h}\left(1-\frac{\sigma}{\sigma_{w}}\right) \\
& V_{u}=A \frac{\sigma_{w}}{\xi} \sqrt{\frac{\sigma}{\sigma_{w}}+1}
\end{aligned}
$$

Relation (5)

Relation (6)

In the above relation, $\mathrm{Mu}$ and $\mathrm{Vu}$ show the bend strength and shear strength while $\sigma$ is the compressive stress resulted from vertical loads and $\sigma \mathrm{w}$ is the compressive strength of materials. In addition, is $\xi$ the coefficient of distribution of shear stress and $\mathrm{A}$ is the surface area. $\mathrm{L}, \mathrm{h}$ and $\mathrm{t}$ are also length, height and thickness of the element under load, respectively.

\section{Failure Mechanisms Under Earthquake Conditions}

The inertia forces resulting from earthquake exert varying stresses and strains on structural members in relation to earthquake acceleration and masses of structural members (such as walls surrounding the gateway) during seismic movements. As a result, periodic stresses concentrate on the members especially at the corners and surroundings of openings. If the strength of the constituting materials of a structural component exceeds the yield limit, the component demonstrates failure and collapses in the subsequent movements. Depending on the type of the stress overcoming the strength of materials, failure mechanisms are classified as follows: shear stresses leading to slide; diagonal strain stresses caused by the internal shears leading to diagonal cracks; stresses resulting from bending which lead to the crushing; and combination of stresses resulting from bending and twisting which destroy and ruin elements). Studies on the remains of buildings following earthquakes suggest that the method, intensity and range of failure depend on the shape, size, dimensional proportion, material and behavior of constituent materials (strength and ductility) of the buildings as well as the earthquake intensity. Figure (7) shows different failure mechanisms that may be involved in the failure of piers between openings (Source: [5]).

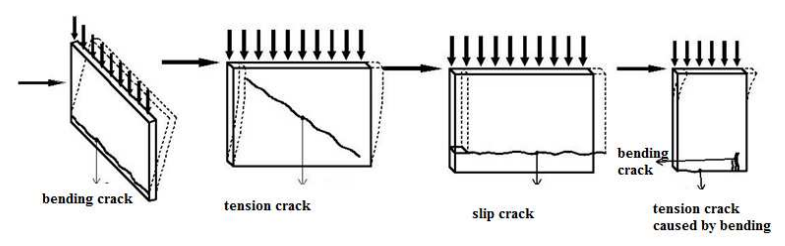

Figure (7). Different failure mechanisms of openings walls under gravity and earthquake loads (source: [5])

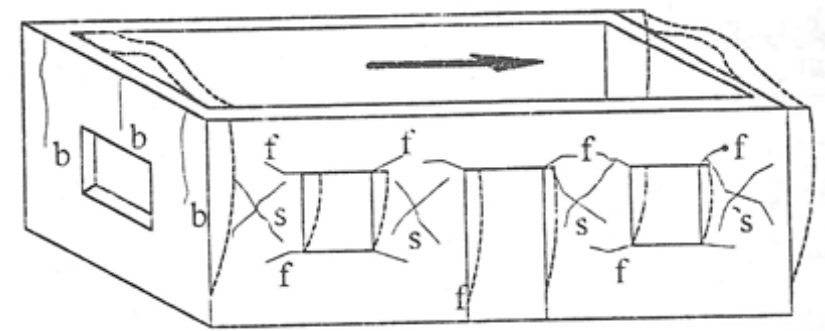

Figure (8). Probable failure mechanisms: (b) off-plane bending-induced cracks; (s) diagonal tension cracks; $(f)$ bending-induced tension cracks (source: [5], www.9ktenews.com)

\section{Discussion and Conclusion}

An overview of the existing theoretical relations and experiences of the damages caused by previous earthquakes indicates that in addition to the type of materials and intensity of earthquake, dimensional proportion, size of sides, geometry and position of openings embedded on walls can also have direct effect on the resistance of buildings to seismic loads. Gateways, windows and closets are considered different forms of openings. Hence, researchers have always tried to develop new design criteria by considering the aforementioned principles. Accordingly, a number of suggestions and criteria, which are mainly derived from the relevant codes, are presented as the research results in the following.

1. Since sharp corners (angles) of openings provide for the concentration of stress and failure of margins of openings, it is recommended to use arches to avoid the use of angled corners on the margins of gateways and openings. Figure (9) depicts this effect. 

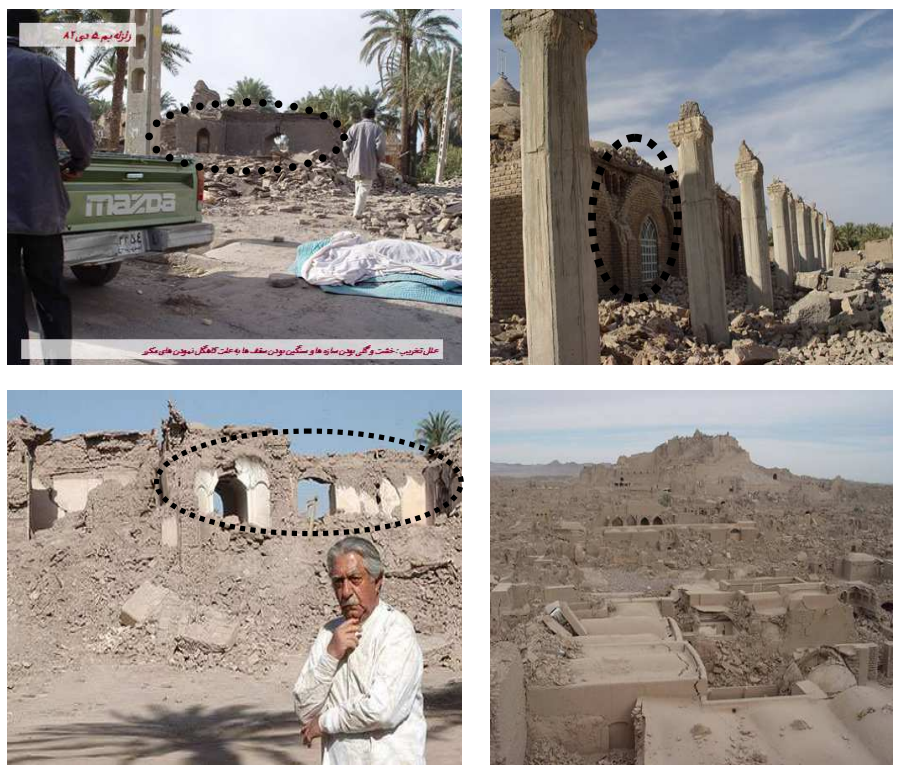

Figure (9). The remaining components are the result of a lack of concentration of stress and the arched nature of openings (Source: [4])

2. Openings shall be embedded in similar positions beneath one another (Fig. 10).
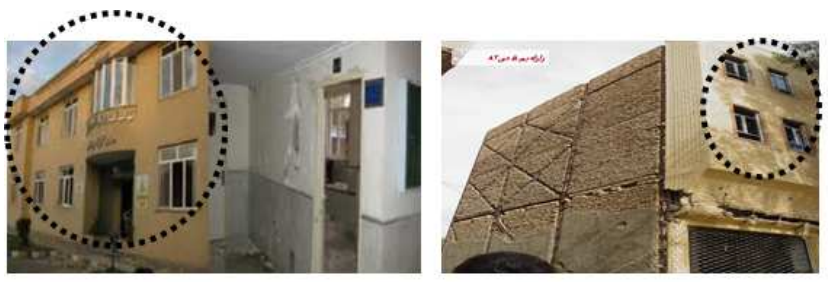

Figure (10). a) one of the reasons for sustainability of buildings is the application of the criteria for openings (source: [3]); b) one of the reasons for sustainability of buildings is the application of the criteria for openings (source: fa.azadnegar.com)

3. The sum of the surface areas of walls at each floor and in each direction shall not be less than $4 \%$ of the total surface area of the story.

4. If actual values of opening dimensions exceed $30 \%$ of the recommended (allowable) values, reinforced concrete coils have to be used at the top and bottom of openings. These coils shall be connected together using other vertical coils used on the sides of each opening.

5. Openings shall be embedded in walls that are exposed to less intense vertical loads.

6. Openings shall be placed outside of the area that is expected to be under the direct effect of loads concentrated on load bearing beams.

7. Openings shall be installed symmetrically so as to distribute the existing stiffness and strength uniformly in the two orthogonal directions of the building.

8. The upper level of openings shall include one horizontal level.

9. Openings shall not cross the ceiling coils.

According to the Iranian Code 2800, it is recommend to avoid construction of wide openings. It is also recommended to embed openings at the center of walls. Moreover, according to this code the following constraints shall be taken into account in the construction of structural walls with openings:

10. The sum of areas of openings shall not exceed $1 / 3$ of the area of the wall housing the openings.

11. The sum of lengths of openings shall not exceed $1 / 2$ of the length of the wall housing the openings.

12. The distance between the first opening and the external side of the building (or the beginning of the wall length) shall not be less than $2 / 3$ of the height of the opening or less than $75 \mathrm{~cm}$ unless vertical coils are installed on the sides of the opening.

13. The horizontal distance between two openings shall not be less than $2 / 3$ of the height of the smallest adjacent opening and $1 / 6$ of the sum of all lengths of adjacent openings. Otherwise, the pier between the two openings becomes part of the opening and shall not be considered a structural wall. The lintel placed on this opening shall be continuous with a span length equal to the sum of the lengths of openings and the length of the pier between them.

14. None of the dimensions of the openings shall have a length of less than $2.5 \mathrm{~m}$. Otherwise, the sides of openings shall be equipped with vertical coils connected to the horizontal upper and lower coils of the story. In addition, it is recommend to reinforce the openings by anchoring the lintel of the opening and connecting it to vertical lateral coils. 

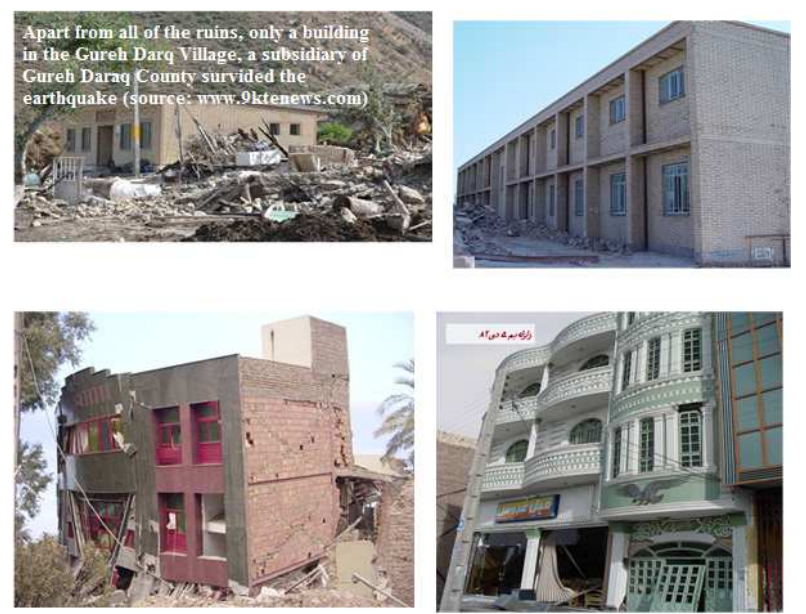

Figure (11). According to expert opinions, these buildings survived the earthquake due to the application of criteria for the design and construction of openings (source: [4])

\section{References}

[1] Muhammad Ibrahim, Zareyi. An introduction to world architecture. Fan Avaran Publications, 2012

[2] Armi Parsa and Afsoon Mahdavi. Meymand Village, M.A. Thesis. Islamic Azad University of Kerman, 1998.
[3] Jalil Shahi. Structural Members. Yazd Universoty, 2000

[4] Kerman Engineering System Organization. Bam Earthquake report CD. 2003

[5] Fariborz, Nateq Elahi, Mehrtash, Motamedi. Design and construction of earthquake-resistant buildings. Nourpardazan Publications, 2003.

[6] Alireza Zeraati. Visual report of the earthquake of December 14, 2014, Bam County, Kerman. 2003

[7] Behrouz Mohebi Moqadam. An introduction to seismic enhancement methods for the existing buildings. Fadak Isatis Publications, 2008

[8] Khosrow Bargi. Principles of earthquake engineering,Tehran Universoty, 2000

[9] Saeed Saeedpour. Earthquake and earthquake-resistant buildings. Salehin Publications, 1999

[10] Ali Asqar Taheri Behbahani. A philosophical approach to computational criteria for buildings under earthquake conditions. Housing Research Center, 1996

[11] Hujjatullah, Adeli. Small-scale buildings in earthquake prone regions. Dehkhoda Publications, 1982

[12] Housing Research Center. Code for the design of earthquakeresistant buildings, 2800-84 standard. Publication no. 253 